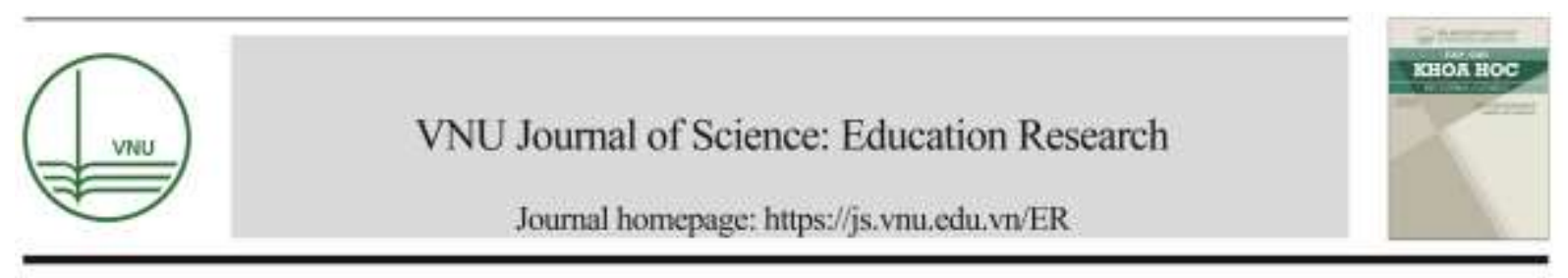

Review Article

\title{
English Language Education in Rural Areas: Current Issues, Complexities and Ways Forward
}

\author{
Pham Huy Cuong* \\ University of Economics and Law, Vietnam National University Ho Chi Minh City, \\ Linh Xuan, Thu Duc, Ho Chi Minh City, Vietnam
}

Received 01 June 2021

Revised 24 June 2021; Accepted 24 June 2021

\begin{abstract}
Despite various challenges confronting teachers, learners and other stakeholders, English language education in rural settings remained relatively underexplored. This study reviews contemporary research on the global and local constraints confronting language teaching and learning in rural areas with a view to proposing measures for boosting the quality of education specifically for the context of Vietnam. The findings uncover a number of limitations in facilities and funding for language education, shortages of teaching staff and the deployment of English curricula. The study also reveals that such learning conditions impact significantly on students' motivation as well as the associations they develop with language learning. These problems are attributable to inequities in educational policy, financial support and endeavors to account for the discrepancies existing in different learning settings. Such insights provide important implications for policy makers, school administrators, teachers and parents in formulating approaches to tackling such issues and the complexities resulting from contextual elements.
\end{abstract}

Keywords: English language education, rural settings, current issues, ways forward, Vietnam education.

\section{Introduction}

While English language education has become a global phenomenon [1, 2], teachers and learners from rural areas experience numerous constraints that significantly impact on the quality of teaching and learning, learners' learning opportunities, attitudes and resilience [3, 4]. The challenging

\footnotetext{
${ }^{*}$ Corresponding author.

E-mail address: cuongph@uel.edu.vn

https://doi.org/10.25073/2588-1159/vnuer.4538
}

socio-economic conditions and limited financial support for these areas impose severe constraints on educational stakeholders, teachers, parents and particularly learners. In defining rurality, researchers tend to focus on the rural-urban divide based on criteria such as geographical features, population density, local incomes, poverty rate, and access to social public services $[5,6]$. Such distinctions fail to address the nexus of societal and personal elements, and the dynamics existing in the rural environment in which individuals are not necessarily subjected to the adversities 
exhibited in their contexts [7]. Rather than viewing places as fixed and static entities, this study draws on the interpretation of rural areas as involving "social processes" that take account of "the way in which we live, work, play, desire, and, hopefully, cooperate" [8]. This contributes to delineating the complexities in conceptualizing rurality for more concise depiction of rural settings [5]. Drawing on the global and local literature on contemporary practices in English language education, this study aims to pinpoint prominent issues concerning the teaching and learning of English in rural settings worldwide and Vietnam and propose ways forward for Vietnam with consideration of the dynamic roles of different educational stakeholders.

\section{Literature Review}

\subsection{English Language Education in Vietnam}

Vietnam's foreign language development was shaped by its history of foreign domination, including languages such as Chinese (over a thousand years of China's invasion), French (France's colonisation from 1859 to 1954), English (American domination from 1954 to 1975) and Russian (Vietnam's socio-political alliance with the USSR prior to the 1990s) [9]. With the rapid integration of Vietnam into the global economy and its expanding relations with other countries in recent years, Wright [10] states that the premise for Vietnam's successful incorporation in the world's economic market consists in the foreign language proficiency of its workforce. In this context, the Vietnam Ministry of Education and Training (MoET) [11] launched a project entitled Teaching and learning foreign languages in the national education system from 2008 to 2020 . Its aim is to ensure that "by 2020, there will have been a dramatically increasing rate of Vietnamese learners who can communicate independently and confidently in foreign languages, study and work in multilingual and multicultural environments" [11]. Given its vital role for Vietnam's socioeconomic development,
English had been integrated into the national secondary and high school curriculum as a compulsory subject by 1972 [12] and an optional subject from Grade Three in major urban primary schools since the 1990s [13]. Some tertiary institutions in Vietnam have implemented English as a medium of instruction in a number of their programs $[14,15]$.

Numerous measures have been implemented in an attempt to improve the quality of English teaching and learning in Vietnam [16]. In its 2008-2020 action plan, MoET [11] endeavors to provide further training for language teachers nationwide in order to narrow the gap in terms of qualifications and teaching skills among teachers in different areas in Vietnam. These goals are reinforced in the revised Project 2020 for the period between 2017 and 2025 with its main emphasis on creating a breakthrough in the quality of language education [17].

\subsection{Bridging the Gaps in English Language Education}

Vietnam is composed of three major geographical regions, namely the North, the Central region, and the South. In recent years, the Vietnamese government has been upgrading rural infrastructure in an attempt to equalize educational attainment nationwide, mainly by providing funds for constructing new schools or renovating the available infrastructure [18-21]. This, however, only helps to improve the facade of these schools, without further investment in the facilities, and rural schools still have a severe lack of dedicated equipment for specific subject areas, especially for English learning and teaching $[22,23]$. Classrooms for language learning are the same as for other school subjects, with fixed seating, making it difficult to conduct communicative activities. Kam [24] states that the shortage of English teaching materials and facilities in Vietnam, especially in remote and rural areas, is "a special challenge to the education authorities". 
While urban students may have diverse access to English learning resources outside the classroom, students in rural schools mainly rely on formal languade education at school. Foreign language centers in rural localities are rare, so are bookstores that sell English reference materials. As a result, English learners in rural areas are in dire need of learning resources and a communicative environment for language practice beyond the school context [22]. The limitations in facilities, language resources and social support for language learning are major threats to the teaching and learning quality in rural high schools [23]. In Ngu's words, "rural areas are seen to be receiving an inferior quality of educational service, and hence a lower overall academic attainment in the population compared with that in the urban areas" [25, pp. 227]. The disadvantageous conditions pose a real challenge to students in rural areas in their language learning.

A majority of households in rural Vietnam work in the agricultural sector [26]. Most parents do manual work and are employed on an occasional basis. Family incomes are unstable due to the nature of their jobs, resulting in their inability to afford good study conditions for their children. According to Holsinger [21], household educational expenditure per high school student in rural areas is only half the amount spent by urban parents. Although the tuition fees of public schools in Vietnam are relatively small, they may still be a financial burden to some parents in rural districts [19, 27]. In some cases, students are required to terminate their schooling to assist their parents by earning money, partly accounting for the dramatic differences in dropout rate between rural and urban schools [28]. According to the World Bank [29] and the mass media in Vietnam, a high proportion of parents in rural areas have very low literacy levels, making it hard for them to provide their children with academic support. Due to such constraints, most students in rural areas have to rely on public education and their own efforts in their studies.

\section{Methodology}

This study reviews research on English language education in rural contexts both in Vietnam and countries with similar educational and socio-economic conditions. The data were collected based on an extensive Google Scholar search using strings of keywords such as "rural language education", "rural settings", "rural constraints", "English language teaching" and "ELT in rural Vietnam". The resulting publications were carefully screened for relevance and 34 studies met the criteria for inclusion. These studies portrayed different aspects of language education in rural settings and concurrently addressed emerging issues that have significant implications for English language education in rural Vietnam. They corresponded with the entries numbered 3, 5, 6, 31-61 in the reference list.

The data were categorized according to major themes derived from content analysis [30]. Specifically, the publications responding to the inclusion criteria were scrutinized for the recurring themes that were more prominent than others. Consequently, five main themes were shortlisted including: i) Issues with facilities and funding for rural schools; ii) The language curricula; iii) Teaching staff quality; iv) Rural learners' motivation to learn English; and v) The values associated with language learning.

\section{Findings}

\subsection{Facilities and Funding for Language Education}

Language education in rural areas is typically characterized as disadvantaged due to its constraints in terms of infrastructure, financial funding, and resources for learning and teaching $[3,5,31,32]$. In the case of rural settings in Vietnam, also including remote and mountainous regions, the lack of classrooms and facilities for language education as well as road access to school remain formidable challenges to local authority. Teachers and students may have to travel long distance to get to school. Such contextual limitations 
undermine the overall operation of language programs, the quality of language teaching and learning, attitudes toward language education, and ultimately the learning outcomes [3, 33-35]. In her study with teenage students from rural South Africa, Omidire [36] finds that the difficulties in daily lives such as the shortage of running water, electricity, and transport, and the home-school distance were major hindrances for students' access to proper language instruction. Such life circumstances are further challenged by the fact that South African students residing in rural areas lack exposure to social networks whereby they attached "no tangible value in the teaching and learning materials with an urban content that do not represent their significance" [37, pp. 2]. Similarly, the severe lack of socio-economic amenities is ubiquitous in rural Bangladesh, leading to high drop-out rate, low literacy levels and the underrepresentation of English in the academic domain [38, 39]. Limited investments in the infrastructure for education are also attributable to the inequality of access to language resources as well as impeding the effectiveness and efficiency of language programs in rural schools in China, Thailand and Vietnam [31, 32, 40].

\subsection{Language Curricula}

While the teaching and learning of English is strongly promoted in non-English speaking countries around the world, the design of the language curriculum adopts a rather homogeneous approach with little consideration of the discrepancies existing in the national demography and geographical differences. The policy of deploying the same language program nationwide irrespective of learners' socio-economic and regional background is common in many countries such as China, Malaysia, Thailand and Vietnam [3, 31, 41-43]. For instance, English is a mandatory subject from Grade 3 to Grade 12 in the national curriculum in Vietnam which is implemented consistently all over the country with the same statement of learning outcomes, time frames, language contents and assessment procedures
[44]. Such practices have given rise to educational inequities that substantially widen the rural-urban gaps in terms of language literacy, achievement and retention rate $[3,37$, 39, 45, 46]. The uniform nature of the English curricula with the lack of consideration of socio-economic variations across geographical regions also poses conspicuous obstacles for teachers, learners and other stakeholders in rural communities as they lack access to dedicated amenities and an immediate environment for language practice [34, 37, 47, 48]. Evidently, learners in rural areas depend primarily on formal lessons at school in rather challenging learning conditions and have limited opportunities for language practice outside classrooms. This has led to their absolute reliance on the school curricula for English which may not sufficiently account for their individual needs as well as provide support for those who fall behind.

\subsection{Shortage of Qualified Teachers of English}

Language teachers in rural areas have been reported to be insufficient in quantity and lack resources as well as adequate professional preparation for working in such contexts $[5,36$, 44, 49]. The shortage of qualified teachers for English language education is one of the major problems confronting rural schools impeding the possibility of catering for the needs of learners $[3,6,31,32,36,48]$. There have also been grave concerns over teachers' language proficiency and expertise in language teaching [3, 5, 50-52]. In the case of Vietnam, recent statistics in the mass media has revealed that an alarning number of teachers, especially those from rural schools, fail to meet the language requirement imposed by MoET [53]. They also have very limited access to professional development. Program, resulting in rather obsolete approaches to language teaching and poor classroom management strategies that foster a positive language learning environment. In relation to these issues, Hansen-Thomas et al., [50] point out that "teachers need to develop specialized skills and strategies to understand the cultural and linguistic challenges 
faced by students; to more effectively engage students from the time the teacher enters the classroom until the teacher leaves" (pp. 308-309). The limitations in terms of facilities and language resources also make it hard for teachers to effectively conduct classroom activities and adopting certain innovative approaches to teaching [3, 36, 48, 54]. This points to the need to prepare trainee teachers for working in diverse teaching settings, including rural contexts; however, teacher education programs have unfortunately failed to address the potential issues that these teachers may encounter $[5,31,50]$.

\subsection{Learners' Motivation to Learn English}

Given the challenging life circumstances and learning conditions in rural areas, learners display differing levels of motivation, resilience and attainment in English language studies $[3,36,43,45,55,56]$. Framing his study from a self-system approach to L2 motivation, Lamb [35] worked with ten adolescent students in rural Indonesia using survey responses and interview data. His study shows that the majority of the participants were aware of the value of learning English for their upward social mobility and developed diverse visions of language use. They claimed to expend effort to learn English and adopt various learning strategies; however, Lamb [35] emphasized the fact that "there is no evidence that any of them were following a plan or had any pedagogic guidance; activities appeared to be idiosyncratic and spontaneous" (pp. 21). These students also showed their lack of confidence in using English for communication. In a similar study from a self-system perspective, Zulkefly and Razali [43] analyze the impacts of the learning conditions between urban and rural schools on secondary school learners' exposure to English input, motivation and language attainment. The findings revealed that learners from rural areas had less access to language and lower linguistic achievement than their urban counterparts. A striking feature of their study was that these two groups of learners developed motivational profiles and appreciation of the importance of learning English that were highly analogous. Truong's [2017] study with 1235 Vietnamese university students from different regions and educational backgrounds also reveals the same situation in which students from rural and remote areas exhibited a low level of L2 confidence and motivation due to the financial and resource limitations hindering their language learning [57]. Further, while rural learners expressed lower self-efficacy than those from urban backgrounds, they tended to invest more effort in language learning. Such resilience and willingness to learn were also identified among students from rural South Africa and Spain as they were aware of their shortcomings and aspired to a vision of bridging their social-economic gap [36, 55]. Conversely, there are cases in which learners were discouraged from learning English due to the lack of an environment for authentic communication [31, 34, 43, 47] or were entangled in the vicious circle of poverty or other social concerns that may thwart their motivation [6, 31, 36, 39, 54].

\subsection{Values Associated with Language Learning}

Learners' attitudes towards learning English and their expended efforts are largely attributable to the practical values of language use as well as parental involvement in language education $[3,38,43,45,50,58-60]$. To many learners and their families, proficiency in English has a life-changing power for career opportunities and upward social mobility $[3,35$, 36, 40, 61]. Lamb's study shows that English is seen as a means of social advancement and has versatility in realizing the varying ambitions of many of his participants including international travel, international social networks, academic success, socially respected career, and self-fulfillment [35]. In the same vein, education in general and language learning in particular are seen as the 'top priority' for success in life in rural contexts in Vietnam [40] or as "the agent of social mediation" for improving one's socio-economic status in rural South Africa [36, pp. 2]. In contrast, Hayes [31] points out the fact that the 
role of English is not always transparent in certain rural areas in Thailand where "English was regarded as a foreign language, with no immediate usefulness and without prestige" (pp. 310). Such opposing views of English account for the different degrees of parental involvement and investment in children's language education. Whereas some rural parents in many parts of the world voice their strong support [3, 35, 36, 40, 43, 49], others express doubts about the practical value of language learning $[31,47,50]$ or financially fail to provide their children with adequate access to resources for learning $[54,59]$.

\section{Conclusion and Ways Forward for Vietnam}

This study provides glimpses of English language education in rural areas, its constraints and the complexities arising from policies, teaching and learning conditions, curricula, teaching staff and the associations attached to language learning. These challenges can be mediated through the collaboration and actions undertaken by various stakeholders in the educational system including policy makers, school administrators, teachers, parents and learners $[3,5,9,10,16]$.

Firstly, the top priority is to ensure equity of access to English, and the resources and support for learners in rural areas. Maximizing learners' exposure to English and their learning opportunities could be achieved by shifting governmental investments in English language education to rural areas [3, 10] and aligning national and local policy on education [11, 40]. In addition, Barrio [41] argues that "stakeholders from the school district and around the community play key roles in addressing any challenge" confronting English language education in rural contexts (pp. 71). Such involvement of multiple players consists in a high degree of socialization of education through appealing for funding and other types of support from corporates and societal groups as well as forming partnerships with local communities $[7,14]$.
Secondly, as discussed earlier, the lack of professional development programs for teachers is a major deterrent to the feasibility of language education in rural settings. Therefore, teacher training which entails pre-service and in-service programs is one of the essential elements contributing to tackling the shortage of qualified teachers and enhancing the quality of English language education [5, 10, 27, 42]. Ensuring sufficient teaching staff also requires developing preferential policies for teachers working in rural areas by means of financial and professional incentives to foster their commitment and retention [28, 40, 43]. Concurrently, teachers can establish a teaching forum as a "community of practice" [44] whereby they can share their experiences, concerns and initiatives, so together they can overcome the challenges confronting their teaching and professional practices.

Thirdly, closer collaboration between teachers and parents can substantially alleviate issues pertinent to English language education in rural contexts. A large number of studies have shown that parents in rural areas show mounting educational concerns and are proactive in their children's language learning [13, 16, 18, 21]. As Erling et al., [4] observe, "People may even be willing to invest significantly in English language education, making sacrifices for their children's education and putting it before other resources, which may also be [more] needed in such contexts" (pp. 20). However, little has been discussed about the specific areas of cooperation between teachers and parents. Regular meetings and dialogues between school administrators and parents are highly needed as a way to gain more profound insights into the lifeworld of learners, their circumstances, parental expectations as well as the degrees and areas of educational involvement they can accommodate [45-47]. Although communication between teachers and parents will possibly incur problems as they may hold differing perspectives, "the articulating of differences and truly listening to differences offers teachers fertile soil for thinking outside familiar frames of reference" 
[46, pp. 24]. In other words, such collaborating experiences contribute to developing mutual understanding and empathy among all parties concerned as a way for ensuring the quality of education, creating favorable conditions for learning as well as strengthening home support for language learning.

Finally, as the primary agents in the learning process, learners should be made aware of the utility value of language learning overarching their own idiosyncrasies, backgrounds and goals. Learning English has been widely identified as a "a means to climb up the social ladder" [48], consolidating the rewards of pursuing it. However, Omidire [14, pp. 16] propounds that "Learners in rural areas need support to help actualize their dreams and hopes for a future where they can move away from their current context" (pp. 16). In addition to providing learners from rural areas with adequate access to English and an environment for regular practice, it is no less important to ignite their interest in learning English and fostering their resilience. These elements may be mitigated by learners' other life and household concerns or their failure to see the immediate needs of using English that undermine their motivation and commitment [9, 21, 37]. Therefore, teachers and parents can work together in raising learners' awareness of potential benefits of learning English and help them envisage the versatility of English for employability and other future prospects.

\section{References}

[1] D. Graddol, English Next, London, British Council, 2006.

[2] Kirkpatrick, R. Sussex (eds.), English as An International Language in Asia: Implications for Language Education, London, Springer, 2012.

[3] Y. G. Butler, English Language Education Among Young Learners in East Asia: A Review of Current Research (2004-2014), Language Teaching Vol. 48, No. 3, 2015, pp. 303-342.

[4] E. J. Erling, P. Seargeant, M. Solly, English in Rural Bangladesh, English Today, Vol. 30, No. 4 , 2014, pp. 15-21.

[5] M. R. Coady, They Just Don't Know Who We Are: Rural English Learner Teacher Education, in
J. I. Liontas (ed.), The TESOL Encyclopedia of English Language Teaching, John Wiley and Sons, 2019, pp. 1-6.

[6] M. J. Irvin, J. L. Meece, S. Y. Byun, T. W. Farmer, B. C. Hutchins, Relationship of School Context to Rural Youth's Educational Achievement and Aspirations, Journal of Youth and Adolescence, Vol. 40, 2011, pp. 1225-1242.

[7] L. Ebersöhn, R. Ferreira, Rurality and Resilience in Education: Place-based Partnerships and Agency to Moderate Time and Space Constraints, Perspectives in Education, Vol. 30, No. 1, 2012, pp. 30-42.

[8] K. D. John, D. R. Ford, The Rural Is Nowhere: Bringing Indigeneity and Urbanism into Educational Research, in W. M. Reynolds (ed.), Forgotten Places: Critical Studies in Rural Education, New York, Peter Lang, 2017, pp. 3-14.

[9] P. T. T. Hang, Impacts of Vietnam's Social Context on Learners' Attitudes towards Foreign Languages and English Language Learning: Implications for Teaching and Learning, Asian EFL Journal, Vol. 11, No. 4, 2009, pp. 169-88.

[10] S. Wright, Language Education and Foreign Relations in Vietnam, in J. W. Tollefson (ed.), Language Policies in Education: Critical Issues, London, Lawrence Erlbaum Associates, 2002, pp. 225-44.

[11] MOET, Teaching and Learning Foreign Languages in the National Education System from 2008 to 2020, Hanoi, Vietnam, 2008.

[12] N. X. Vang, English Language Teaching in Vietnam Today: Policy, Practice and Constraints, in H. W. Kam, R. Y. L. Wong (eds.), English Language Teaching in East Asia Today: Changing, Policies and Practices, Singapore, Eastern Universities Press, 2003, pp. 455-462.

[13] N. T. M. Hoa, Primary English Language Education Policy in Vietnam: Insights from Implementation, Current Issues in Language Planning, Vol. 12, No. 2, 2011, pp. 225-249.

[14] D. T. K. Anh, N. T. M. Hoa, L. T. T. Truc, The Impacts of Globalisation on EFL Teacher Education through English as a Medium of Instruction: An Example from Vietnam, Current Issues in Language Planning, Vol. 14, No. 1, 2013, pp. 52-72.

[15] L. D. Manh, English as a Medium of Instruction at Tertiary Education System in Vietnam, The Journal of Asia TEFL, Vol. 9, No. 2, 2012, pp. 97-122.

[16] L. Q. Chon, Why is English Language Teaching in Vietnam Remains Ineffective? Vietnam Education News, https://giaoduc.net.vn/giao-duc- 
24h/tai-sao-day-tieng-anh-o-viet-nam-khong-hieuqua-post193491.gd/, 2018 (accessed on: May 15 ${ }^{\text {th }}$ 2021) (in Vietnamese).

[17] MOET, Decision No. 2080/QD-TTg on the Approval, Adjustment and Supplement of The Project Teaching and Learning Foreign Language in The National Education System in the Period 2017-2025, Hanoi, Vietnam, Vietnam National Politic Publications, 2017.

[18] J. D. London, Contemporary Vietnam's Education System: Historical Roots, Current trends, in J. D. London (ed.), Education in Vietnam, Singapore, Institute of Southeast Asian Studies, 2011, pp. 1-56.

[19] World Bank, Vietnam Development Report 2010: Modern Institutions, Poverty Reduction and Economic Management Sector Unit, East Asia and Pacific Region, 2009.

[20] D. B. Holsinger, Inequality in the Public Provision of Education: Why It Matters, Comparative Education Review, Vol. 49, No. 3 , 2005, pp. 297-310.

[21] D. B. Holsinger, The Distribution of Education in Vietnam: Why Does Equality Matter?, in Y. Hirosato, Y. Kitamura (eds.), The Political Economy of Educational Reforms and Capacity Development in Southeast Asia: Cases of Cambodia, Laos and Vietnam, London, Springer, 2009, pp. 191-216.

[22] N. D. Chinh, L. T. Linh, T. H. Quynh, N. T. Ha, Inequality of Access to English Language Learning in Primary Education in Vietnam: A Case Study, in H. Zhang, P. W. K. Chan, C. Boyle (eds.), Equality in Education: Fairness and Inclusion, Boston, Sense Publishers, 2014, pp. 139-153.

[23] L. Anh, Teaching and Learning English in Challenging Areas: Multiple Difficulties, Quang Ninh Electronic News, https://baoquangninh.com.vn/day-va-hoc-tienganh-o-vung-dac-biet-kho-khan-kho-chong-kho2361963.html/, 2017 (accessed on: May 15 ${ }^{\text {th }}$, 2021) (in Vietnamese).

[24] H. W. Kam, English Language Teaching in East Asia Today: An Overview, Asia Pacific Journal of Education, Vol. 22, No. 2, 2002, pp. 1-22.

[25] V. Q. Ngu, Social Disparities in Vietnam: The Case of Poverty Reduction and Educational Attainment, in P. Taylor (ed.), Social Inequality in Vietnam and the Challenges to Reform, Singapore, Institute of Southeast Asian Studies, 2004, pp. 208-235.

[26] World Bank, Vietnam Development Report 2012: Market Economy for a Middle-Income Vietnam, 2011.
[27] World Bank, Education in Vietnam: Development History, Challenges and Solutions, 2005.

[28] B. T. Quyen, School Dropout Trends in Vietnam from 1998 to 2006, in J. D. London (ed.), Education in Vietnam, Singapore, Institute of Southeast Asian Studies, 2011, pp. 152-170.

[29] World Bank, Vietnam Development Report 2014-Skilling up Vietnam: Preparing the Workforce for a Modern Market Economy, 2013.

[30] P. Mayring P, Qualitative Content Analysis, Forum: Qualitative Social Research, Vol. 1, No. 2, 2000.

[31] D. Hayes, Language Learning, Teaching and Educational Reform in Rural Thailand: An English Teacher's Perspective, Asia Pacific Journal of Education, Vol. 30, No. 3, 2010, pp. 305-309.

[32] Z. Rao, P. Yu, Teaching English as A Foreign Language to Primary School Students in East Asia, English Today, Vol. 35, No. 3, 2019, pp. 16-21.

[33] R. B. Kaplan, R. B. Baldauf, N. Kamwangamalu, Why Educational Language Plans Sometimes Fail, Current Issues in Language Planning, Vol. 12, No. 2, 2011, pp. 105-124.

[34] R. Kubota, S. Mckay, Globalization and Language Learning in Rural Japan: The Role of English in the Local Linguistic Ecology, TESOL Quarterly, Vol. 43, No. 4, 2009, pp. 593-619.

[35] M. Lamb, Your Mum and Dad Can't Teach You!: Constraints on Agency among Rural Learners of English in the Developing World, Journal of Multilingual and Multicultural Development, Vol. 34, No. 1, 2013, pp. 14-29.

[36] M. F. Omidire, Experiencing Language Challenges in a Rural School: Implications for Learners' Life Aspirations, Early Child Development and Care, 2019, pp. 1-19.

[37] M. L. Malebese, M. F. Tlali, Teaching of English First Additional Language in Rural Learning Environments: A Case for Problem-Based Learning, International Journal of Inclusive Education, Vol. 24, No. 14, 2019, pp. 1540-1551.

[38] E. J. Erling, P. Seargeant, M. Solly, Q. H. Chowdhury, S. Rahman, Attitudes to English as a Language for International Development in Rural Bangladesh, London, British Council, 2012.

[39] M. O. Hamid, R. B. Baldauf Jr, English and Socio-Economic Disadvantage: Learner Voices from Rural Bangladesh, The Language Learning Journal, Vol. 39, No. 2, 2011, pp. 201-217.

[40] C. Pham, C. White, Rural Students' Motivation for Learning English: Implications for Transition to Tertiary Education, in J. Albright (ed.), English 
Tertiary Education in Vietnam, London, Routledge, 2019, pp. 132-144.

[41] P. Methitham, P. B. Chamcharatsri, Critiquing ELT in Thailand: A Reflection from History to Practice, Journal of Humanities, Naresuan University, Vol. 8, No. 2, 2011, pp. 57-68.

[42] X. V. Nguyen, English Language Teaching in Vietnam Today: Policy, Practice and Constraints, in H. W. Kam, R. Y. L. Wong (eds.), English Language Teaching in East Asia Today: Changing Policies and Practices, Singapore, Eastern Universities Press, 2003, pp. 455-462.

[43] F. Zulkefly, A. B. Razali, Malaysian Rural Secondary School Students' Attitudes toward Learning English as a Second Language, International Journal of Instruction, Vol. 12, No. 1, 2019, pp. 1141-1156.

[44] J. Albright (ed), English Tertiary Education in Vietnam, London, Routledge, 2019.

[45] M. Lamb, A Self System Perspective on Young Adolescents' Motivation to Learn English in Urban and Rural Settings, Language Learning, Vol. 62, No. 4, 2012, pp. 997-1023.

[46] T. T. T. Nguyen, English Language Policies for Vietnamese Primary Schools and Issues of Implementation in Rural Settings, Journal of Asia TEFL, Vol. 9, No. 4, 2012, pp. 115-134.

[47] M. Byram, From Foreign Language Education to Education for Intercultural Citizenship: Essays and Reflections, Clevedon, Multilingual Matters, 2008.

[48] H. W. Kam, R. Y. L. Wong (eds.), English Language Teaching in East Asia Today: Changing, Policies and Practices, Singapore, Eastern Universities Press, 2003.

[49] M. Gardiner, Education in Rural Areas, Johannesburg, South Africa, Centre for Education Policy Development, 2008.

[50] H. H. Thomas, L. G. Richins, K. Kakkar, C. Okeyo, I Do Not Feel I Am Properly Trained to Help Them! Rural Teachers' Perceptions of Challenges and Needs with English-Language Learners, Professional Development in Education, Vol. 42, No. 2, 2016, pp. 308-324.

[51] M. Lamb, The Impact of School on EFL Learning Motivation: An Indonesian Case Study, TESOL Quarterly, Vol. 41, No. 4, 2007, pp. 757-780.

[52] T. T. Le, S. Chen, Globalization and Vietnamese Foreign Language Education, in J. Albright (ed.), English Tertiary Education in Vietnam, London, Routledge, 2019, pp. 16-27.

[53] N. Hue, Vietnamese Teachers of English are Underqualified in Language Proficiency Tests, Tien Phong News, https://tienphong.vn/giao-vienngoai-ngu-thi-muoi-khong-dat-mot post1096976.tpo/, 2019 (accessed on: April 15 $5^{\text {th }}$, 2021) (in Vietnamese).

[54] X. Qian, R. Smyth, Measuring Regional Inequality of Education in China: Widening Coast-Inland Gap or Widening Rural-Urban Gap? Journal of International Development, Vol. 20, No. 2, 2008, pp. 132-144.

[55] R. Alejo, A. P. Píriz, Urban vs. Rural CLIL: An Analysis of Input-Related Variables, Motivation and Language Attainment, Language, Culture and Curriculum, Vol. 29, No. 3, 2016, pp. 245-262.

[56] C. White, C. Pham, Time in the Experience of Agency and Emotion in English Language Learning in Rural Vietnam, Innovation in Language Learning and Teaching, Vol. 11, No. 3, 2017, pp. 207-18.

[57] C. B. Truong, The Motivation of Vietnamese University Students to Learn English: A Study Using the Expectancy-value Model of Academic Motivation, $\mathrm{PhD}$ Thesis, New South Wales, Australia, The University of Newcastle, 2017.

[58] Y. G. Butler, Parental Factors in Children's Motivation for Learning English: A Case in China, Research Papers in Education, Vol. 30, No. 2, 2015, pp. 164-191.

[59] Hajar, Motivated by Visions: A Tale of a Rural Learner of English, The Language Learning Journal, Vol. 6, No. 4, 2018, pp. 415-429.

[60] M. Lamb, The Struggle to Belong: Individual Language Learners in Situated Learning Theory, in P. Benson, L. Cooker (eds.), The Applied Linguistic Individual: Sociocultural Approaches to Identity, Agency and Autonomy, Bristol, Equinox, 2013, pp. 32-45.

[61] D. Hayes (ed), Primary English Language Teaching in Vietnam, Primary Education Regional Seminar, Bangkok, Thailand, British Council, 2008.

[62] H. Rude, K. J. Miller, Policy Challenges and Opportunities for Rural Special Education, Rural Special Education Quarterly, Vol. 37, No. 1, 2018, pp. 21-29.

[63] B. L. Barrio, Special Education Policy Change: Addressing the Disproportionality of English Language Learners in Special Education Programs in Rural Communities, Rural Special Education Quarterly, Vol. 36, No. 2, 2017, pp. 64-72.

[64] D. Nunan, The Impact of English as a Global Language on Educational Policies and Practices in the Asia-Pacific Region, TESOL Quarterly, Vol. 37, No. 4, 2003, pp. 589-613. 
[65] D. T. T Nguyen, English Language Teacher Education in Vietnam: A Case Study of Localized Approaches to the Concept of Method at a Rural Vietnamese College, $\mathrm{PhD}$ Thesis, University of Technology Sydney, Australia, 2018.

[66] E. Wenger, Communities of Practice: Learning, Meaning, and Identity, New York, Cambridge University Press, 1998.

[67] S. Panferov, Increasing ELL Parental Involvement in Our Schools: Learning from the Parents, Theory into Practice, Vol. 49, 2010, pp. 106-112.

[68] J. M. Shim, Involving the Parents of English Language Learners in A Rural Area: Focus on
The Dynamics of Teacher-parent Interactions, Rural Educator, Vol. 34, No. 3, 2013, pp. 18-26.

[69] S. You, J. T. Nguyen, Parents' Involvement in Adolescents' Schooling: A Multidimensional Conceptualisation and Mediational Model, Educational Psychology: An International Journal of Experimental Educational Psychology, Vol. 31, No. 5, 2011, pp. 547-558.

[70] A. Sharma, English as a Facilitator of Social Mobility in India: The Instrumentality vs. Identity Debate in Language Policy Research, English Today, 2020, pp. 1-4. 